Bates College

SCARAB

$1-2019$

\title{
Understanding Barriers and Opportunities for Adoption of Conservation Practices on Rented Farmland in the US
}

Pranay Ranjan

Chloe B. Wardropper

Francis R. Eanes

Bates College, feanes@bates.edu

Sheila M.W. Reddy

Seth C. Harden

See next page for additional authors

Follow this and additional works at: https://scarab.bates.edu/faculty_publications

\section{Recommended Citation}

Ranjan, P., Wardropper, C.B., Eanes, F.R., Reddy, S.W., Harden, S.C., Masuda, Y.J.,Prokopy, L.S.. (2019). Understanding barriers and opportunities for adoption of conservation practices on rented farmland. Land Use Policy. 80, 214-223. https://doi.org/10.1016/ j.landusepol.2018.09.039 


\section{Authors}

Pranay Ranjan, Chloe B. Wardropper, Francis R. Eanes, Sheila M.W. Reddy, Seth C. Harden, Yuta J. Masuda, and Linda S. Prokopy 
Understanding barriers and opportunities for adoption of conservation practices on rented farmland in the US

Ranjan, P., Wardropper, C.B., Eanes, F.R., Reddy, S.M.W., Harden, S.C., Masuda, Y.J., \& Prokopy, L.S. (In Press, Land Use Policy)

\section{Abstract}

Agricultural conservation programs often focus on farm operators when promoting conservation practices. However, much of U.S. farmland is owned by landowners not directly involved in farm operations. Rental arrangements on these lands can dis-incentivize the adoption of conservation practices that could improve soil health, water quality, and land values. To date, agricultural conservation policy has largely ignored the role of non-operating landowners (NOLs) and rental arrangements. We help improve the evidence-base for policy by identifying barriers to adoption of conservation practices on rented farmlands. Analysis of forty interviews with NOLs, operators, farm managers and university extension personnel in Iowa, Illinois, and Indiana revealed five categories of barriers: cash rent lease terms, rental market dynamics, information deficits/asymmetries, cognitive/interpersonal, and financial motivations. Some barriers, such as risk aversion and farm aesthetics were expressed by both NOLs and operators, while other barriers, such as status quo bias and annual renewal of leases were only expressed by NOLs and operators, respectively. To overcome barriers to conservation, interviewees recommended improving communication between NOLs and operators and modifying cash rent lease terms in order to build in flexibility for equitable sharing of risks and rewards. Agricultural conservation programs could readily apply these results—-possibly working with intermediaries (e.g., farm managers, lawyers) - to offer communication and lease tools and assistance to NOLS and operators. Future research should evaluate the efficacy of these conservation interventions and how intermediaries affect the balance of power between NOLs and operators. 


\section{Keywords}

Non-operating landowners, absentee landowners, operators, rented farmland, conservation barriers, barrier expression

\section{Introduction}

Most agricultural conservation programs focus on farm operators when promoting conservation practices that promote soil health and improved water quality such as cover crops, no-till and nutrient management (e.g., USDA-NRCS, 2018). However, 39 percent of all U.S. farmland is rented (USDA-NASS, 2015), and 80 percent of that rented land is owned by non-operating landowners (NOLs). NOLs are those who own farmland and rent it to a farm operator, rather than farming it themselves (Bigelow et al., 2016). There is some evidence that when the owner is not the operator, there is a lower probability of conservation practice adoption than on owneroperated land (Petrzelka et al., 2013; Soule et al., 2000; Ulrich-Schad et al., 2016).

Questions regarding how NOLs view conservation on their land and what motivates them to get involved with conservation are under-researched (Petrzelka et al., 2013; Ulrich-Schad et al., 2016). More work has investigated attitudes and behaviors of owners of other types of land, particularly private forestland owners (Finley and Kittredge, 2006; Rickenbach and Kittredge, 2009). However, our understanding of conservation attitudes and behaviors of NOLs and operators with respect to adoption of conservation practices on rented farmland remains thin. Using social and behavioral science to identify these barriers and approaches to overcome them is critical to designing successful, evidence-based conservation programs (Reddy et al., 2017). With the goal of filling this research gap, we present findings from interviews conducted with NOLs, operators, farm managers and university extension personnel in Indiana, Illinois, and 
Iowa. In particular, we were interested in understanding the barriers to adoption of conservation practices that NOLs and their operators face. While limited past work has identified barriers for NOLs to adopt conservation practices (see Carolan, 2005), in this study, we focus on developing an understanding of the barriers faced by both NOLs and their operators. We also asked public (Extension) and private advisors what barriers they have found to adoption in working with clients. The barriers, as well as potential solutions, identified through interviews will improve the evidence base for sustainable agricultural and land use policy.

\section{Literature Review}

Ownership of land by NOLs is growing worldwide (Petrzelka, 2012). In the U.S., NOLs of farmland are a unique population in comparison to farm operators. NOLs tend to be older than farm operators and are more likely than farmers to be female, with 37 percent of NOLs being female, compared to just 10 percent of farm operators on rented land (Bigelow et al., 2016). These owners tend to be either retired farmers, inheritors of family-owned land, or purchasers of land for investment or recreation (Petrzelka et al., 2012). Residential NOLs live on or near the land they rent or lease to others, while absentee NOLs live in a different county, state, or country from the location of their land (Ulrich-Schad et al., 2016). Comparing residential and absentee NOLs, absentee NOLs are less likely than residential NOLs to be from farming backgrounds or to have knowledge about agriculture (Petrzelka et al., 2012).

Only 18 percent of NOLs are involved in conservation practice decisions on their land (Bigelow et al., 2016), although NOL participation varies by the type of decision. Decisions on short-term farm management practices, such as cultivation practices, crop choice, and harvesting, are commonly made with no input from NOLs. Because farm ownership is an investment, NOLs are more likely to be involved in long-term decisions, including adopting permanent conservation 
practices such as contour terraces and implementing infrastructural improvements, such as tile drainage (Petrzelka et al., 2009).

Barriers to implementing conservation practices on farmland with NOLs have been acknowledged in the academic literature and white papers on U.S. non-operating farmland owners since the late 1970s (Pampel and van Es, 1977). Although there have been relatively few studies on this population, we use this extant literature to identify barriers in four primary categories: lease terms, information deficits, interpersonal or cognitive barriers, and NOL financial needs.

Lease terms - including lease length and type - have been identified as a barrier to conservation adoption. Seventy percent of leases on U.S. farms are single-year contracts (Bigelow et al., 2016). Yet while lease renewal is common - 84 percent of U.S. farmland acres have been rented to the same tenant for over three years (Bigelow et al., 2016) - evidence on the effect of annual versus multi-year leases on adoption of conservation practices is thin. Multi-year leases are often recommended to promote sustainable agricultural practices (e.g., Cox, 2011), or hypothesized to have an effect on conservation (Maye et al., 2009; Soule et al., 2000). But the effects of these arrangements are either not quantified, or not tested for statistical significance with respect to conservation adoption (Maye et al., 2009). Qualitative evidence points to the importance of multi-year leases for promoting soil health and conservation. Carolan et al. (2004) found that the uncertainty of one-year leases inhibited tenants' willingness to adopt sustainable practices, particularly those whose benefits accrue over time (e.g., cover crops).

Like annual leases, cash leases (as opposed to crop-share or flexible leases) are currently the most common type of lease (70 percent of agricultural leases) (Bigelow et al., 2016), affording both the NOL and operator the ease of an up-front acre price. In this arrangement, the annual rent 
is set, typically near the end of the calendar year, with no additional adjustments. In Carolan et al.’s (2004) study, operators thought cash leases made sustainable farming more challenging, because they concentrate risk on the operator. Cash rent is more risky for the operator because the operator pays a set rent regardless of the harvest or input costs (Roesch-McNally et al., 2018). There is some quantitative evidence that cash leases are less likely than crop-share leases to be associated with adoption of conservation practices. For example, Soule et al. (2000) found that cash renters were less likely than share-renters to use conservation tillage.

Information deficits are a second category of conservation barrier identified in the literature. Carolan et al. (2004) found that farmers already engaged in or who were interested in getting into sustainable agriculture perceived extension and other agricultural advisers, traditional sources of agronomic recommendations, as lacking technical knowledge needed to advise tenants and landowners on sustainable methods. Conservation practice information rarely targets NOLs, especially NOLs living out-of-state or who do not fit the typical farmer profile, such as women or investors (Petrzelka et al., 2009).

Interpersonal or cognitive barriers make up a third category, including communication difficulties between a NOL and their operator stemming from geographic distance, power dynamics, gender, age, or status quo bias. Uneven power dynamics may exist between a NOL and operator, often in ways that deviate from a typical landowner-tenant relationship. Gilbert and Beckley (1993), for instance, found that the NOLs they surveyed had little to no power in their relationships with their tenants; most NOLs were "only passive recipients of rent” (p.570).

This dynamic is not always present, but can be exacerbated by age or gender. The average age of a farm operator is 58, while the NOL average is 66.5 (USDA-NASS, 2015). Petrzelka and Marquart-Pyatt (Petrzelka and Marquart-Pyatt, 2011) propose that older NOLs may be less 
active on their land than younger NOLs, and thus may be less likely to initiate conservation practices on the farm. Older NOLs may also be less likely to consider long-term alternative land uses such as agroforestry (Arbuckle et al., 2009). Power dynamics are particularly pronounced in relationships between female NOLs and male operators. Thirty-seven percent of principal NOLs are female, and they hold about 25\% of the farmland acreage that was rented out in 2014 (Petrzelka et al., 2018). Female NOLs often feel a sense of exclusion from farm decisions and a lack of technical knowledge, which in turn may lead them to self-censor (Carolan et al., 2004; Carter, 2016). Female NOLs are generally less involved in farm decision making than males, including decisions pertaining to conservation (Constance et al., 1996; Petrzelka and MarquartPyatt, 2011). Supportive networks of conservation-minded NOLs can counteract some of these dynamics, although these networks are difficult to access when the NOL lives far away (Constance et al., 1996; Petrzelka et al., 2013).

On the other side of the relationship, operators may be hesitant to "rock the boat" of the relationship with their NOL by trying new conservation practices (Carolan, 2005). Agricultural fields have traditionally been seen as aesthetically pleasing if crop rows are straight, weeds are gone, and hedge rows are trimmed back. This view can clash with some sustainable practices, which encourage cover crops, field edge buffers, and/or leaving crop residue on the surface. Ulrich-Schad et al. (2016) found that 59 percent of in-state Midwestern NOLs and 39 percent of those out-of-state said that "keeping the land looking nice" had a lot of influence on their choice of renter.

NOL financial needs can also play a role in conservation decisions. NOLs who prioritize shortterm rental income over long-term land value appreciation may be less motivated by benefits of sustainable agriculture, which often take many years to occur. Carolan et al. (2004) found that 
operators expressed a desire for information that compares the profitability of conventional practices to sustainable practices to defend their interest in sustainable practices to NOLs. A survey of NOLs in the Great Lakes Basin by Petrzelka and Marquart-Pyatt (2011) found that female NOLs’ odds of involvement in conservation practices decreased when they indicated their reliance on the land for income as high, but this variable was not significant for male respondents.

\section{Methods}

The data for this study come from semi-structured in-depth interviews with NOLs, operators, farm managers and university extension personnel in Indiana, Illinois and Iowa. We chose this study area because these states have the highest levels of nitrogen loss in the Mississippi River Basin (Alexander et al., 2008), and at the same time have the highest proportion of rented farmland (Bigelow et al., 2016). 40.4 million acres of farmland is rented out across these three states (USDA-NASS, 2015).

The interview guide was developed based on an extensive literature review which also informed the subsequent coding framework used to analyze the interviews. Forty interviews - eight operators, $21 \mathrm{NOLs}^{1}$, six farm managers, and five university extension personnel - were conducted between March and May 2017, both in person and over the phone. Initial NOL and operator interviewees were identified from sampling frames used in prior survey research by Purdue University’s Natural Resources Social Science lab, while farm managers and university extension personnel were identified and recruited through the researchers’ professional networks.

\footnotetext{
${ }^{1}$ Three NOLs in our study were both operator and landowner, i.e., while they operated some of their land, they were NOLs on the land they rented out. We interviewed these landowners only about the land they were renting out. For consistency, and ease of presenting data, we are referring to all the 21 landowners who rented out land as NOLs.
} 
Snowball sampling was used with the initial interviewees to diversify the pool of study participants (Patton, 1990). For example, initial NOL interviewees were asked to identify their operators and/or other NOLs as potential interviewees so that we obtained a diversity in terms of attributes identified below. Interviews were conducted until saturation was reached, meaning until the point when additional interviews were not uncovering any new themes (Charmaz, 2006).

NOLs were recruited in order to diversify their representation in terms of age, gender, farm size, and whether or not they were in-state/out-of-state. Operators were recruited in order to diversify their representation in terms of farm size, age, and when possible were recruited based on a referral from the participating landowner from whom they rent. We had three NOL-operator pairs in our study. Interviews ranged from 30 minutes to an hour and half, and were structured around five core thematic areas²: basic demographic and background information (e.g., farm size, crops grown); lease arrangements; the landowner-operator relationship, including communication and power dynamics; attitudes towards conservation; and barriers to conservation practice adoption on rented land.

Three of the authors spent considerable time conducting the interviews, and developing the coding framework both deductively - i.e., as a result of our understanding of current conservation barriers from the literature, and inductively - by following a process of reflexive iteration (Srivastava and Hopwood, 2009). The process of reflexive iteration involved reading and rereading interview transcripts, and using the emerging themes to develop categories and sub-categories. Two of these authors went back and forth during the coding process to refine the

\footnotetext{
${ }^{2}$ Please refer the interview guide for more details (see Appendix 1).
} 
coding framework and ensure intercoder reliability. The coding framework was refined following the process of reflexive iteration, as new sub-categories emerged. After refining the coding framework, it was used to conduct an intercoder reliability test on a subset of four interviews, and achieved a Cohen’s kappa of 0.78, indicating adequate consistency between the two coders. For any emerging theme to be included in the following results section as a conservation barrier, at least two or more interviewees had to independently identify it. The third author who conducted interviews but did not code was able to look at the developed themes and ensure face validity with their recollection of the interviews. Qualitative data analysis was conducted using NVivo 11.

\section{Results}

We first present demographic/background information pertaining to NOLs and operators who were interviewed in this study. Second, we discuss the five categories of barriers for adoption of conservation practices on rented farmland that we identified. Recognizing that conservation barriers differentially affect NOLs, operators, or both, in this section, we make a conceptual distinction between barrier expression and identification. Specifically, we conceptualize identification of a barrier and its attribution to self as ‘barrier expression’. A NOL identifying asynchronous commodity price and cash rental rate trends as a conservation barrier and attributing it as a barrier to self is an example of barrier expression. Similarly, an operator identifying annual renewal of leases as a conservation barrier and attributing it as a barrier to self is an example of barrier expression. However, an operator identifying that NOLs lack of agronomic knowledge acts as conservation barrier for NOLs is not an example of barrier expression. Likewise, an operator identifying status quo bias as a conservation barrier for other operators is not an example of barrier expression. Moreover, because conservation barriers are 
attributable either to NOLs, operators, or both, identification of a barrier by a farm manager (FM) and/or an extension personnel (E) is not barrier expression. For example, a FM identifying lack of asset performance data as a barrier attributable to NOLs is not an example of barrier expression. In the last section, we make recommendations for overcoming conservation barriers on rented farmland.

\subsection{NOL-operator demographic/background information}

Of the 21 NOLs interviewed in this study, 14 lived in the state where their farmland was located, and seven lived out-of-state. Of the NOLs, six leased to family members (all in-state owners), while three used a farm manager (all out-of-state owners). The remaining NOLs leased to operators they had known, either as neighbors or through their personal networks. The average age of NOLs in our study was 69 years and their formal education ranged from high school to postgraduate degree. The average age of operators in our study was 59 years and their formal education ranged from high school to bachelor's degree. The average ages of both NOLS and operators are generally consistent with prior research, which have shown NOLs to be somewhat older than operators. Characteristics of interviewees are summarized in Table 1. 
Table 1. Study participants, by type, state, and gender

\begin{tabular}{|l|l|l|l|}
\hline $\begin{array}{l}\text { Interviewee } \\
\text { group }\end{array}$ & $\begin{array}{l}\text { Total by } \\
\text { group }\end{array}$ & $\begin{array}{l}\text { Numbers } \\
\text { by state }\end{array}$ & Gender \\
\hline $\begin{array}{l}\text { Landowner, } \\
\text { in-state }\end{array}$ & 14 & $\begin{array}{l}\text { IA (6) } \\
\text { IL (6) } \\
\text { IN (2) }\end{array}$ & $\begin{array}{l}\text { M (11) } \\
\text { F (3) }\end{array}$ \\
\hline $\begin{array}{l}\text { Landowner, } \\
\text { out-of-state }\end{array}$ & 7 & $\begin{array}{l}\text { IA (3) } \\
\text { IN (4) }\end{array}$ & $\begin{array}{l}\text { M (5) } \\
\text { F (2) }\end{array}$ \\
\hline $\begin{array}{l}\text { Farm } \\
\text { operator }\end{array}$ & 8 & $\begin{array}{l}\text { IA (4) } \\
\text { IN (2) } \\
\text { IL (2) }\end{array}$ & M (8) \\
\hline $\begin{array}{l}\text { Farm } \\
\text { manager }\end{array}$ & 6 & $\begin{array}{l}\text { IA (5) } \\
\text { IL (1) }\end{array}$ & $\begin{array}{l}\text { M (5) } \\
\text { F (1) }\end{array}$ \\
\hline $\begin{array}{l}\text { Extension } \\
\text { personnel }\end{array}$ & 5 & $\begin{array}{l}\text { IA (2) } \\
\text { IL (3) }\end{array}$ & M (5) \\
\hline
\end{tabular}

\subsection{Barriers pertaining to cash rent lease terms}

\subsubsection{Annually renewed leases}

Annual renewal of leases made operators feel insecure about the longevity of their farmland tenancy and uncertain about receiving the future benefits of conservation practices. Expressing this barrier, an operator mentioned, “...short-term lease arrangement is the biggest barrier in my mind. If you're going to keep the land 10 years, and you have the organic matter higher and less erosion, it [adopting conservation practices] was worth it, I am convinced...I think year-to-year leases are a big barrier...” Operators perceive several conservation practices as capital improvements, in which costs are immediate, but benefits accrue over the long-term. For example, an operator must buy seeds for cover crops each year, but it may take multiple years before cover crops produce soil health benefits (e.g., increased soil organic matter and waterholding capacity) ${ }^{3}$. Operators, therefore, felt uncertain about getting their investment back if the

\footnotetext{
${ }^{3}$ Cover crops may produce benefits immediately by reducing fertilizer runoff and soil erosion.
} 
landowner might terminate their lease in the following year. A farm manager identifying annual renewal of leases as a conservation barrier mentioned, "If it's a capital investment, and a lot of these conservation practices are...there's going to be a reluctance or a reticence if you're [an operator] just on a year-to-year term on your lease."

\subsubsection{High rental rate}

NOLs setting increasingly high rental rates may discourage operators from adopting conservation practices, while encouraging them to adopt aggressive management practices detrimental to the long-term productivity of the farmland. For example, an operator mentioned, “...when they're [NOLs] going for a high dollar rent...it seems like that's where the most abusive farming practices start coming into play. It's all about everything in that moment and the land suffers." Identifying high cash rent as a barrier, a farm manager mentioned, "Some people [NOLs] are purely there for money I can make off my farm...So then the lease terms are such that they're either at such a high rate [cash rent] that the farmer has to do whatever it takes to make their money, whether or not it's good for the farm." High cash rent affected operators' conservation decision making on leased land versus the land they owned. Expressing this as a barrier, an operator mentioned, “...I am sure there is some immediate benefit [associated with adoption of cover crops], but there is a substantial part of it that is a long-term benefit as far as building organic matter. That's a multi-year decade kind of thing. That's why I only do it on what I own. The other farms [that I lease], cash rents are just so high, there is just no space there to spend extra money [for adoption of cover crops]." 


\subsubsection{Lease negotiation timeline}

An integral component of a land tenure arrangement is negotiating lease terms between the NOL and the operator. NOLs are required to convey their intent of modifying lease terms, including the cash rent amount, to their operator/s by sending a lease modification notice, prior to September 1 in Iowa, October 31 in Illinois, and at least three months' in advance in Indiana. The actual lease year, with modified lease term/s, begins from March 1 across the three states. We found support for negotiating leases in January/February, much closer to March 1. Highlighting the importance of negotiating lease terms late, a farm manager mentioned, "If you did it [the negotiation] in January/February...you know more what the next year is [in terms of crop yields and prices]...but when you got to renegotiate a lease in August [of the previous year], then you are 15 months before the next crop gets out of the field...you are so far away that you don't know what's really happening...this is one of the factors that effects the continuity of tenants [operators], and that effects conservation and everything else.” On the contrary, we also found support for negotiating leases in August/September of the previous year, much earlier than

March 1. Highlighting the importance of negotiating lease terms early, a farm manager mentioned, “... a landlord [NOL] needs to understand that maybe we need to negotiate this lease quite a bit earlier than we have in the past, to give that operator the knowledge that he's going to have that farm, and yes, go ahead and get it planted for cover crops." Expressing how lease negotiation timeline plays on their mind when making long-term decisions on the land they rent, an operator mentioned, “When you are negotiating [lease terms] in January, sometimes you think, “ “Well, I am not going to get it [the land] next year.” ” Overall, the evidence highlights the importance of lease negotiation timelines - albeit with conflicting preferences - for conservation decision making on rented farmland. 
Table 2. Conservation barriers pertaining to cash rent lease terms

\begin{tabular}{|c|c|c|c|c|c|}
\hline \multirow{2}{*}{$\begin{array}{c}\text { Conservation } \\
\text { Barriers Category }\end{array}$} & \multirow{2}{*}{ Barriers } & \multicolumn{2}{|c|}{$\begin{array}{c}\text { Barrier } \\
\text { Expression }^{\mathbf{a}}\end{array}$} & \multicolumn{2}{|c|}{$\begin{array}{c}\text { Barrier } \\
\text { Identification }^{\mathbf{a}}\end{array}$} \\
\cline { 2 - 6 } & & NOL $^{\mathbf{b}}$ & $\mathbf{O}^{\mathbf{b}}$ & FM $^{\mathbf{c}}$ & E $^{\mathbf{c}}$ \\
\hline \multirow{3}{*}{$\begin{array}{c}\text { Cash rent lease } \\
\text { terms (L) }\end{array}$} & Annual renewal & & $\checkmark$ & $\checkmark$ & $\checkmark$ \\
\hline & High rental rate & & $\checkmark$ & $\checkmark$ & \\
\cline { 2 - 6 } & Negotiation timeline & & $\checkmark$ & $\checkmark$ & \\
\hline
\end{tabular}

Notes:

${ }^{a}$ Barrier expression = barrier identification + attribution to self; please refer to section 4 for more details.

${ }^{\mathrm{b}}$ A check sign $(\checkmark)$ indicates that the barrier was expressed by NOLs/Operators. Absence of a check sign indicates that the barrier was not expressed by NOLs/Operators.

${ }^{c}$ A check sign $(\checkmark)$ indicates that the barrier was identified by Farm Manager (FM)/Extension Personnel (E). Absence of a check sign indicates that the barrier was not identified by FM/E.

\subsection{Barriers pertaining to rental market dynamics}

\subsubsection{Rental market competitiveness}

Competitiveness of the rental market was identified as a barrier for adoption of conservation practices. Limited supply of land available for rent, combined with a very high demand for cash rent lease arrangement, leads to operators offering high cash rents to NOLs despite declining commodity process. As a result, operators' profit margins are reduced, which in turn discourages them from adopting conservation practices. For example, a farm manager mentioned, "For every acre of ground that becomes available to rent, there are 15 guys [operators] out there wanting it and they bid it up. So, they spread themselves really thin on the front end just to lease the ground...in flush times they might be willing to do conservation practices... but when margins are super tight, they're far less willing to do that." Moreover, competition for rented land heightens an operators' insecurity about lease renewal, thereby discouraging any form of management change that might jeopardize the rental relationship. Expressing this as a barrier, an operator mentioned, "We've got huge [large-scale] farmers that are real good about sending 
letters to people [NOLs], and say, " "I'll give you X amount to rent your ground,"” and you need some security that that's not going to happen. If you are really working to improve the ground for them [NOLs] and doing what you can [for example, adopt cover crops], it's not fair to get sold out."

\subsubsection{Commodity market and cash rent trends}

Lack of synchronicity between the relatively small decline in cash rents (only about 3-5\% over the past 4 years) and the comparatively larger commodity price decline reduces operators' profit margin and thus discourages conservation. Expressing this as a barrier, an operator mentioned, "I do a lot of conservation work on the ground that I farm...but when you are right up against tight margins [between commodity price and cash rent], I wouldn't do it." Awareness of the current commodity market trends made NOLs hesitant to talk to their operators about conservation practices. Expressing this as a barrier, a NOL mentioned, “...we are three years into a [declining commodity price market]. So, I would be more hesitant [to talk to my operator about conservation practices] because of the way the economics are more in our favor today than the tenants [operators]. So, asking for some conservation practice that was further impacting their economics, it would be tougher today." Farm managers and extension personnel also identified this as a barrier. For example, a farm manager mentioned, “...the economics [of commodity market prices] that are out there right now, [operators'] profit margins are going to compress. It's a harder sell doing some of these conservation practices." 
Table 3. Conservation barriers pertaining to rental market dynamics

\begin{tabular}{|c|c|c|c|c|c|}
\hline \multirow{2}{*}{$\begin{array}{c}\text { Conservation } \\
\text { Barriers Category }\end{array}$} & \multirow{2}{*}{ Barriers } & \multicolumn{2}{|c|}{$\begin{array}{c}\text { Barrier } \\
\text { Expression }^{\mathbf{a}}\end{array}$} & \multicolumn{2}{|c|}{$\begin{array}{c}\text { Barrier } \\
\text { Identification }^{\mathbf{a}}\end{array}$} \\
\cline { 2 - 6 } & & NOL $^{\mathbf{b}}$ & $\mathbf{O}^{\mathbf{b}}$ & FM $^{\mathbf{c}}$ & $\mathbf{E}^{\mathbf{c}}$ \\
\hline \multirow{2}{*}{$\begin{array}{c}\text { Rental market } \\
\text { dynamics (R) }\end{array}$} & Competitiveness & & $\checkmark$ & $\checkmark$ & \\
\cline { 2 - 6 } & Commodity/rent trends & $\checkmark$ & $\checkmark$ & $\checkmark$ & $\checkmark$ \\
\hline
\end{tabular}

Notes:

${ }^{a}$ Barrier expression = barrier identification + attribution to self; please refer to section 4 for more details. ${ }^{\mathrm{b}}$ A check sign $(\checkmark)$ indicates that the barrier was expressed by NOLs/Operators. Absence of a check sign indicates that the barrier was not expressed by NOLs/Operators.

${ }^{c}$ A check sign $(\checkmark)$ indicates that the barrier was identified by Farm Manager (FM)/Extension Personnel (E). Absence of a check sign indicates that the barrier was not identified by FM/E.

\subsection{Barriers pertaining to information deficits/asymmetries}

\subsubsection{Unawareness of conservation practices and programs}

Perhaps one of the most important barriers to NOLs suggesting or requiring the adoption of conservation practices is NOLs' fundamental unfamiliarity with what specific conservation practices are, how they can be integrated into a farming operation, and how they can provide both on-farm and off-farm benefits over various time horizons. Several NOLs were unable to identify any specific conservation practices at all, much less comment on which practices, if any, their operator currently uses. For example, a NOL mentioned, “I don't know what those [conservation] practices would be to be candid with you." Expressing this barrier, another NOL mentioned, "I would have to defer [your question about conservation practices on my land] to him [my operator]. He's a good farmer. I'm going to guess that he's...doing low and no till and some of those other things that-- that would be have to be a question for him.” These NOLs tended to speak in abstract generalities about conservation, or expressed a very narrow understanding of what conservation entails (e.g., enrollment in set-aside programs like CRP (Conservation Reserve Program). These NOLs were particularly likely to express hesitance 
about suggesting their operator adopt one or more conservation practices, and tended to defer most frequently to the operator's assumed expertise. For example, a NOL mentioned, "I'm not really well-enough informed [about conservation practices and programs] to make any suggestions that way...He's much better informed than I am.” Even among the NOLs who have at least a basic understanding of specific conservation practices (e.g., no-till or cover crops), their lack of thorough knowledge about the practice’s implications (e.g., cost over time, management and equipment needs/changes) could make them similarly hesitant to encourage their operator to adopt conservation practices.

\subsubsection{Lack of operational and/or agronomic knowledge}

NOLs’ lack of general knowledge about agricultural operations - including equipment, constraints, and operational timing associated with common farming practices - led to their hesitance to intervene in farm operations or suggest changes in management (e.g., adoption of conservation practices) to the operator. Expressing this barrier, a NOL mentioned, "I'm a little bit reluctant because I don't feel like I know enough about current farming practices or even conservation practices to make suggestions to him [operator]...I guess I would have to learn quite a bit to be more comfortable.” Describing their experience of answering the questions NOLs pose, an extension personnel mentioned, "Sometimes we get people [NOLs] calling about...the practices farmers do...how is that going to affect $X, Y$, and Z... [these NOLs] did not grow up on a farm. Or maybe they even farmed for 20 or 30 years but they've been away from it for a while. And so, they really don't have huge grasp on what those farmers are up to today." This lack of understanding may lead to NOL apathy, disengagement, and a general lack of sensitivity towards the operational and financial constraints that operators must navigate on a daily and seasonal basis. 


\subsubsection{Lack of asset performance data}

Some NOLs lack access to crucial data about the value and productivity of their land, resulting in a distorted perception of the actual influence and power they retain in their rental relationship. Examples of asset performance data include annual yield data, input/operational costs, regional land value trends, and the long-term impact of various management practices on their landasset's value. This information is much more readily known (and often generated) by the operator, resulting in information asymmetry between NOL and operator when negotiating new or existing lease terms. For example, a farm manager mentioned, “Landowners don't always know the difference between a farm and the circumstances, and why there's a difference in [land] value here. And then it puts them on a mistrust level... [On the contrary]...farmer has all the information. They know all the production down there. They know what's going on in a way that the landowners aren't going to..." Such asymmetry may result in a NOL feeling less motivated to suggest or require changes in management practices that would result in improved soil health and the long-term maintenance of their land-asset's value.

\subsubsection{Unawareness of market competitiveness}

Depending on their background knowledge and level of engagement in the NOL-operator relationship, NOLs demonstrated varying levels of awareness regarding the competitiveness of the land rental market. Typically, NOLs were much less aware - compared to operators - of the competitiveness of the rental market, leading to information asymmetry. NOLs without a robust understanding of just how competitive the rental market has become tended to express the (potentially misguided) perception that they cannot stipulate anything to the operator for fear of losing them. Identifying this as a barrier, an extension personnel mentioned, “There are people [NOLs] that will stay with the same farmer even if they know it's not in their best interest...And 
they'd like to change [the operator] but they just don't. Because how do you find another farmer?" Like other barriers that reflect the real and perceived power differentials between NOL and operator, this asymmetry reinforces NOLs' aversion to anything that might disrupt the status quo. For example, a farm manager mentioned, "Most of the landlords don't want to ruffle any feathers, but don't like the farming that their tenant's [operator's] doing. They are really nervous about not having a tenant [operator] at all, and so they're worried that if they put their foot down, they won't have any tenant [operator]...I don't think they realize that they're in a landowner's market.”

\subsubsection{Unawareness of agriculture’s negative externalities}

In addition to their lack of general agronomic and operational knowledge, some NOLs lack awareness about agriculture’s negative social-ecological impacts (e.g., on water quality, biodiversity/wildlife habitat, and climate change). For example, talking about the impact of agriculture on water quality, a NOL mentioned, “I honestly, I just-- I don't think about it...And we don't look at ourselves as being part of the solution, but it's like, “"Well, we have a waterway going through our farm, why aren't we protecting it?" " Operators, on the other hand, may be more aware of the negative impacts of agriculture in general, but may not consider it a pressing issue for which they are personally responsible, potentially affecting their willingness to adopt conservation practices. For example, a farm manager mentioned, "I think it's [water quality] a real issue, but a lot of the tenants [operators] are like, “"Eh, it's not an issue.””

\subsubsection{Unawareness of supporting resources}

In addition to lacking asset performance data, some NOLs are unaware of resources that might provide them with these and other data relevant to their NOL-operator relationship. Examples 
include lack of NOL awareness of the services and information provided by county extension services, such as workshops on NOLs rights and responsibilities, templates for multi-year leases, information about conservation practices/programs, or the provision of annual (publicly available) survey data on average county rental rates. Other deficits include lacking access to or awareness of NOL peer-to-peer networks (e.g., women’s learning circles ${ }^{4}$ ). Identifying this barrier, an extension personnel mentioned, “...We do have a few landowners [NOLs] that call here routinely. But I don't think that non-farm landowners probably are aware, as much as farmers, of that-- of not only that resource [extension as a provider of information and services], but a lot of other ones.”

\subsubsection{Unawareness of rights/obligations}

Some NOLs lack awareness of what they are entitled (by law or social norms) to ask of their operators, as well as the potential means (e.g., lease stipulations) for doing so. When coupled with poor communication with the operator, this lack of awareness can cause conflict with the operator when long-overdue capital improvements need to be made. For example, some NOLs may think that taking care of terraces is the operator's responsibility, and assume that the operator should have maintained them annually themselves instead of asking NOLs to improve them after 5-10 years. Describing this situation, a farm manager mentioned, "I get it all the time cleaning out the terraces, they [operator] think the owner [NOL] should clean out the terraces. Right now [in this scenario], I felt for the sake of the owner, well, you were farming all these years, you should clean that out." Operators, on the contrary, may think that it is NOLs' responsibility since terracing is considered long-term/capital improvement to the land. Other

\footnotetext{
${ }^{4}$ These are meetings organized by NOL focused conservation groups, exclusively for women NOLs and operators to provide them the tools they need to make farm management decisions, including adoption of conservation practices and programs.
} 
NOLs are unaware of the means by which they can legally terminate a lease with an operator with whom they are no longer satisfied.

Table 4. Conservation barriers pertaining to information deficits/asymmetries

\begin{tabular}{|c|c|c|c|c|c|}
\hline \multirow{2}{*}{$\begin{array}{c}\text { Conservation } \\
\text { Barriers Category }\end{array}$} & \multirow[t]{2}{*}{ Barriers } & \multicolumn{2}{|c|}{$\begin{array}{c}\text { Barrier } \\
\text { Expression }^{\mathbf{a}}\end{array}$} & \multicolumn{2}{|c|}{$\begin{array}{c}\text { Barrier } \\
\text { Identification }^{\mathrm{a}}\end{array}$} \\
\hline & & NOL $^{b}$ & $\mathbf{O}^{\mathbf{b}}$ & $\mathbf{F M}^{\mathbf{c}}$ & $E^{c}$ \\
\hline \multirow{7}{*}{$\begin{array}{c}\text { Information } \\
\text { deficits/asymmetries } \\
\text { (I) }\end{array}$} & $\begin{array}{c}\text { Conservation } \\
\text { practices/program }\end{array}$ & $\checkmark$ & & $\checkmark$ & \\
\hline & $\begin{array}{c}\text { Operational/agronomic } \\
\text { knowledge }\end{array}$ & $\checkmark$ & & $\checkmark$ & $\checkmark$ \\
\hline & Asset performance & & & $\checkmark$ & $\checkmark$ \\
\hline & $\begin{array}{c}\text { Rental market } \\
\text { competitiveness }\end{array}$ & & & $\checkmark$ & $\checkmark$ \\
\hline & Ag. externalities & $\sqrt{ }$ & & $\checkmark$ & \\
\hline & Supporting resources & & & & $\checkmark$ \\
\hline & Rights/obligations & & & $\checkmark$ & $\checkmark$ \\
\hline
\end{tabular}

Notes:

${ }^{\text {a }}$ Barrier expression $=$ barrier identification + attribution to self; please refer to section 4 for more details. ${ }^{\mathrm{b}}$ A check sign $(\checkmark)$ indicates that the barrier was expressed by NOLs/Operators. Absence of a check sign indicates that the barrier was not expressed by NOLs/Operators.

${ }^{c}$ A check sign $(\checkmark)$ indicates that the barrier was identified by Farm Manager (FM)/Extension Personnel (E). Absence of a check sign indicates that the barrier was not identified by FM/E.

\subsection{Cognitive/Interpersonal barriers}

\subsubsection{Status quo bias}

NOLs often mentioned the theme of maintaining status quo in their lease arrangement.

Expressing this as a barrier, a NOL mentioned, “I don't think we need to get involved in that [creating a new lease with provisions for conservation] in the [current] lease...just go on like we've been going.” Another NOL, expressing the theme of status quo bias, mentioned, "I guess what I see, what little I know, I'm satisfied with how it seems to be going." Status quo bias also emerged as barrier for adoption of conservation practices on farmland owned and managed by several members of the same family. Expressing this as a barrier, a NOL mentioned, “My 
mom...she's got these views of the way my dad did things...and I'm like, "“look at the neighbor, he's got buffer strips in. He's doing conservation"”...but she didn't [have a conversation with the operator].” Farm managers mentioned that status quo bias made it difficult for them to promote conservation practices to second generation NOLs ${ }^{5}$. Identifying status quo bias as a barrier, an extension personnel mentioned, “...most of them [NOLs] don't want to bring up an issue that's going to put their relationship with their farmer at risk. They don't want change."

\subsubsection{Risk aversion}

Risk aversion was expressed as a theme discouraging adoption of conservation practices on rented farmland. For example, a form of risk aversion we found in this study was associated with the risk of trying a practice like cover crops whose outcomes include so many unknowns. Expressing this barrier, an operator mentioned, “The likelihood of setting yourself up for failure is exponential, I think, with cover crops because you just don't know a lot of things.” Also expressing risk aversion as a barrier, a NOL mentioned, "Cover crop is a little difficult in this area because our season's so short...I'm not opposed to covered crops. It's just that it's a difficult thing to do in this area...” Risk aversion was also mentioned in the context of adoption of conservation practices entailing immediate costs but delayed benefits. Identifying how risk aversion plays on the mind of NOLs when making conservation decisions, a farm manager mentioned, “A lot of these fixes [requiring adoption of conservation practices] might entail taking three or four acres of ground out of production permanently...and it's all for intangible. Because it's nutrient loss...it's stopping erosion and stuff, but none of that is going to translate into profit

\footnotetext{
${ }^{5}$ These NOLs inherited a farm but did not grow up on a farm or in a farming community.
} 
year after year for them [NOLs] that they can save. They have to take it at faith that this is something that needs to be done."

\subsubsection{Aesthetics}

There is a perception among some NOLs that a well-managed farm should have neat rows and appear weed-free (and therefore cover crop and residue free) at all times. Expressing this barrier, a NOL mentioned, "I like the place kept up nice and neat. As far as I want the grass cut along the roadways and stuff and the farmers go ahead and do that." Another common perception that runs counter to conservation recommendations is that the black soil should be tilled and exposed. Identifying this barrier, a farm manager mentioned, "I bet there are a number of landlords out there who are like, “"Nope. I want a black field [tilled field with exposed soils] and I don't want to have any green out there." " These aesthetic expectations can lead to a status quo bias among NOLs or operators, who are reticent to try practices that look unkempt in their eyes.

\subsubsection{Deference to operators}

Deference to operators, sometimes at the expense of conservation adoption, can result from informational asymmetries, risk aversion, and status quo bias. This barrier is characterized by a commonly expressed sentiment that "the tenant [operator] knows best," or "I [the NOL] don't want to interfere with what they're [the operator is] doing, or give the impression that I'm looking over their shoulder." Expressing this barrier, a NOL mentioned, "I feel like then he'd [my operator] feel like, “"Well, she doesn't think I'm taking care of this,"” right, or, “"She doesn't feel like I know what I'm doing."” And I feel like it would make it look like I'm questioning his practices, and I don't want to do that.” This sentiment is most commonly expressed by women and NOLs with no personal farming history (though certainly not 
exclusively so).

\subsubsection{Lack of place attachment and generational differences}

These two barriers were often referenced together, because when farmland passes to the next generation, the children or grandchildren frequently live further away from the land, and do not have the knowledge or opportunity to speak with their operator about management. Other NOLs who lack place attachment include individuals who buy the land for investment without inheritance, which can lead to disengagement and disinterest in conservation. Underlying the theme of a lack of place attachment and generational differences is the notion that when children or grandchildren inherit farmland, they may not have grown up on a farm or in a farming community, so they don't have a reference point for management or they may not feel attached to their farmland. Identifying this barrier, a farm manager mentioned, "I have some clients [second generation NOLs] that have never been on a farm. So why do we need this [conservation practice] now? Because it hasn't been there for the last 75 years, why now? That's a potential hurdle that I've faced...” An operator explained the opposite generational challenge. Some of their NOLs are of an older generation who expect to see exposed black soil after harvest, and are uncomfortable with cover crops. 
Table 5. Cognitive/Interpersonal conservation barriers

\begin{tabular}{|c|c|c|c|c|c|}
\hline \multirow{2}{*}{$\begin{array}{c}\text { Conservation } \\
\text { Barriers Category }\end{array}$} & \multirow{2}{*}{ Barriers } & \multicolumn{2}{|c|}{$\begin{array}{c}\text { Barrier } \\
\text { Expression }^{\mathrm{a}}\end{array}$} & \multicolumn{2}{|c|}{$\begin{array}{c}\text { Barrier } \\
\text { Identification }^{\mathrm{a}}\end{array}$} \\
\hline & & NOL $^{b}$ & $\mathbf{O}^{\mathbf{b}}$ & $\mathbf{F M}^{\mathbf{c}}$ & $\mathbf{E}^{\mathbf{c}}$ \\
\hline \multirow{5}{*}{$\begin{array}{c}\text { Cognitive/Interpers- } \\
\text { onal (C) }\end{array}$} & Status quo bias & $\checkmark$ & & $\checkmark$ & $\checkmark$ \\
\hline & Risk aversion & $\checkmark$ & $\checkmark$ & $\checkmark$ & \\
\hline & Aesthetics & $\checkmark$ & $\checkmark$ & $\checkmark$ & \\
\hline & Deference to operators & $\checkmark$ & & $\checkmark$ & $\checkmark$ \\
\hline & $\begin{array}{l}\text { Lack of place attachment \& } \\
\text { generational differences }\end{array}$ & & & $\checkmark$ & $\checkmark$ \\
\hline
\end{tabular}

Notes:

${ }^{a}$ Barrier expression = barrier identification + attribution to self; please refer to section 4 for more details. ${ }^{\mathrm{b}}$ A check sign $(\checkmark)$ indicates that the barrier was expressed by NOLs/Operators. Absence of a check sign indicates that the barrier was not expressed by NOLs/Operators.

${ }^{c}$ A check sign $(\checkmark)$ indicates that the barrier was identified by Farm Manager (FM)/Extension Personnel (E). Absence of a check sign indicates that the barrier was not identified by FM/E.

\subsection{Barriers pertaining to NOL financial motivations}

\subsubsection{Short-term financial gain mindset}

The motivations of several NOLs toward short-term financial gain was identified as a barrier for adoption of conservation practices. In fact, NOL motivations of financial gain may encourage adoption of practices by operators that are detrimental to the farmland. For example, a NOL, now retired from farming, mentioned, “...some landlords are chasing the almighty dollar... [they rent land to operators] who are mining the farm...trying to maximize short-term yields....” Expressing this barrier, a NOL mentioned, "Well, if that's what they [the operator] wanted to [adopt conservation practice] and they paid me the cash rent, that's up to them." NOLs' fundamental unfamiliarity with conservation practices may also reinforce their short-term financial goal mindset because they don't even see the practices as improving long-term asset value. This barrier overlaps with insufficient information, as farm managers are unable to provide sufficient evidence of the payback that could be expected from a conservation practice such as cover crops. 


\subsubsection{Dependency on farm income}

Retired or older NOLs are frequently dependent on the rent from their farm as their primary source of income. Heavy reliance on farm rental income, especially for elderly NOLs, made it difficult for farm managers and extension personnel to recommend adoption of conservation practice/s that may take time to lead to financial benefits to them. For example, a farm manager mentioned, "Many people [NOLs] live off these farms...if it takes some big dollars [in order to deal with conservation issues] they don't want to borrow money.” This barrier is often interrelated with short-term financial gain mindset, especially if a NOL has immediate needs such as medical payments that must be covered by the farm rent. For example, an extension personnel mentioned, "If [landowners] have some affluence, they're okay, then they tend to buy in on that conservation component. But if this is what's allowing them to buy their medicine, then it's pretty hard to say, “"We're going to terrace this, and it's going to make less money, and it will be good for the environment, but you won't be able to buy your medicine.””

Table 6. Conservation barriers pertaining to NOL financial motivations

\begin{tabular}{|c|c|c|c|c|c|}
\hline \multirow{2}{*}{$\begin{array}{c}\text { Conservation } \\
\text { Barriers Category }\end{array}$} & \multirow{2}{*}{ Barriers } & \multicolumn{2}{|c|}{$\begin{array}{c}\text { Barrier } \\
\text { Expression }^{\mathbf{a}}\end{array}$} & \multicolumn{2}{|c|}{$\begin{array}{c}\text { Barrier } \\
\text { Identification }^{\mathbf{a}}\end{array}$} \\
\cline { 2 - 6 } & & NOL $^{\mathbf{b}}$ & $\mathbf{O}^{\mathbf{b}}$ & FM $^{\mathbf{c}}$ & $\mathbf{E}^{\mathbf{c}}$ \\
\hline $\begin{array}{c}\text { Financial } \\
\text { motivations (M) }\end{array}$ & Short-term financial gain & $\checkmark$ & & $\checkmark$ & $\checkmark$ \\
\cline { 2 - 6 } & Farm income dependency & & & $\checkmark$ & $\checkmark$ \\
\hline
\end{tabular}

Notes:

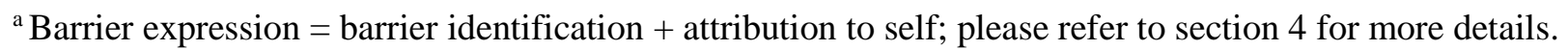
${ }^{\mathrm{b}}$ A check sign $(\checkmark)$ indicates that the barrier was expressed by NOLs/Operators. Absence of a check sign indicates that the barrier was not expressed by NOLs/Operators.

${ }^{c}$ A check sign $(\checkmark)$ indicates that the barrier was identified by Farm Manager (FM)/Extension Personnel (E). Absence of a check sign indicates that the barrier was not identified by FM/E. 


\subsection{Recommendations to overcome conservation barriers}

Several interviewees made recommendations for how to overcome conservation barriers. They suggested that NOLs could be more willing to (1) be flexible with lease terms, (2) offer multiyear leases to address operators' lease renewal insecurity, and (3) incorporate proration into leases. Building flexibility into cash rent lease terms was predominantly suggested by way of NOLs and operators adopting a hybrid/flexible lease, a form of cash rent lease arrangement that accounts for fluctuating markets and uncertain yields, for instance, by not determining the final rental rate until the crop is harvested. Another suggested way of being flexible was NOLs willingness to lower rent, especially if adoption of a conservation practice impacts the short-term yield. Expressing several of the aforementioned recommendations, an operator mentioned, "The biggest thing [NOLs can do is], if they're willing to share in the funding, particularly thinking towards the cover crops...Sharing in the funding and being willing to offer a longer than single year lease." Highlighting the importance of incorporating proration into leases, a farm manager mentioned, "If a tenant [operator] is willing to take the risk and invest money out of his own pocket into [conservation] ...I'll prorate that [investment] over four years or five years...so that...down the road two years you're no longer in that farm, you'll being reimbursed for the three unused years of your investment." The farm manager further added, "Giving stewardship primacy, and financial return for a period of time, a secondary status, that's what an owner [NOL] can do [to promote adoption of conservation practices]."

Recommendations to overcome information deficits/asymmetries and cognitive/interpersonal conservation barriers often highlighted the importance of communication between the NOL and the operator. For example, emphasizing that operators should share both good and bad news with their NOLs, an extension personnel mentioned, "Good communication is key. I tell people 
[operators], if you have a smartphone, you just pull that thing out, and you see something, and you take a picture, and you send it to that landlord. Because they feel so good." Communication between the NOL and the operator also helped in setting the expectations right in a land tenure arrangement and in avoiding a situation of operators perceiving their NOLs to be 'demanding'. Another recommendation was that NOLs should initiate conversation pertaining to adoption of conservation practice. Highlighting this aspect, a farm manager mentioned, "[operators] don't want to go the landowner and suggest that they're going to have to pay for it [a conservation practice] because they don't want to break trust. So there's a lot of pressure...So when the landowner initiates the conversation, it frees up some things." Another recommendation was to educate NOLs about conservation practices and programs. Highlighting this recommendation, a farm manager mentioned, "I think it comes down to education and good communication." Overcoming barriers pertaining to financial motivations of NOLs, especially their short-term financial gain mindset could include educating them about conservation practices and programs. Further emphasizing the need to educate NOLs, a farm manager mentioned, "First they [NOLs] got to be aware of it [conservation practices]...that's the big deal, I think. There are a lot of owners that just don't know."

Recommendations to overcome conservation barriers are summarized in table 7. We also provide specific examples of how these recommendation can help overcome conservation barriers. 
Table 7. Recommendations to overcome conservation barriers

\begin{tabular}{|c|c|c|}
\hline $\begin{array}{l}\text { Conservation Barriers } \\
\text { Category }\end{array}$ & Recommendation & Specific examples/affects \\
\hline \multirow{4}{*}{$\begin{array}{c}\text { Cash rent lease terms } \\
\& \\
\text { Rental market } \\
\text { dynamics }\end{array}$} & \multirow[b]{2}{*}{$\begin{array}{l}\text { Be flexible with } \\
\text { lease terms }\end{array}$} & $\begin{array}{l}\text { Having hybrid leases; helps account for } \\
\text { fluctuating markets and uncertain yields. }\end{array}$ \\
\hline & & $\begin{array}{l}\text { NOLs willingness to lower rent, especially if } \\
\text { adoption of a conservation practice affects } \\
\text { yield }\end{array}$ \\
\hline & $\begin{array}{l}\text { Offer multi-year } \\
\text { leases }\end{array}$ & $\begin{array}{l}\text { Lease longer than } 1 \text { year (typically } 3-5 \\
\text { years); addresses operators’ lease renewal } \\
\text { insecurity }\end{array}$ \\
\hline & $\begin{array}{l}\text { Incorporate } \\
\text { proration into } \\
\text { leases }\end{array}$ & $\begin{array}{l}\text { Having proration agreement written into the } \\
\text { lease; safeguards operators' farm investments } \\
\text { if the lease is terminated }\end{array}$ \\
\hline \multirow{4}{*}{$\begin{array}{c}\text { Information } \\
\text { deficits/asymmetries } \\
\& \\
\text { Cognitive/interpersonal }\end{array}$} & \multirow{3}{*}{$\begin{array}{l}\text { Improve } \\
\text { communication } \\
\text { between NOLs } \\
\text { and operators }\end{array}$} & $\begin{array}{l}\text { Operators sharing both successes and failures } \\
\text { associated with farm management, including } \\
\text { conservation practices; encourages well- } \\
\text { functioning relationship }\end{array}$ \\
\hline & & $\begin{array}{l}\text { NOLs initiating conversation pertaining to } \\
\text { adoption of conservation practices; helps take } \\
\text { 'pressure' off the operator }\end{array}$ \\
\hline & & $\begin{array}{l}\text { Helps set expectations right in a land tenure } \\
\text { arrangement; avoids situation of operators } \\
\text { perceiving their NOLs to be 'demanding' }\end{array}$ \\
\hline & $\begin{array}{l}\text { Educate NOLs } \\
\text { about conservation } \\
\text { practices and } \\
\text { programs } \\
\end{array}$ & $\begin{array}{l}\text { Helps overcome NOLs' information deficits, } \\
\text { resulting in improved communication with } \\
\text { operators }\end{array}$ \\
\hline Financial motivations & $\begin{array}{l}\text { Educate NOLs } \\
\text { about conservation } \\
\text { practices and } \\
\text { programs }\end{array}$ & $\begin{array}{l}\text { Helps NOLs overcome short-term financial } \\
\text { gain mindset }\end{array}$ \\
\hline
\end{tabular}

\section{Discussion and conclusion}

With the goal of understanding the attitudes and behaviors of NOLs and operators, and identifying barriers to adoption of conservation practices on rented farmland, we conducted interviews with NOLs, operators, farm managers and university extension personnel in Indiana, Illinois and Iowa. We identified five categories of barriers to the adoption of conservation practices on rented farmland: (1) barriers pertaining to cash rent lease terms, (2) barriers 
pertaining to the rental market dynamics, (3) information deficit/asymmetry barriers, (4) cognitive/interpersonal barriers, and (5) barriers pertaining to NOL financial motivations.

Several of the barriers identified in the previous literature on NOLs were supported by our study. For example, scholars have identified lease type (i.e., cash rent leases as opposed to crop-share leases $^{6}$ ) as a barrier for adoption of conservation practices (Carolan et al. 2004; Cox, 2011; Maye et al., 2009; Soule at al., 2000). We identified the following cash rent lease terms as barriers: annual renewal of leases, high rental rate, and lease negotiation timeline. These findings advance our understanding of how and why cash rent leases act as a barrier for adoption of conservation practices on rented farmland. Likewise, the information deficit/asymmetry barriers we identified pertaining to NOL's conservation are consistent with those identified by Carolan (2004) and Petrzelka et al., (2009). As well, our findings about the effects of NOL-operator power differentials due to gender, age, and knowledge differences support the findings of prior research (e.g., Bigelow et al., 2016; Petrzelka \& Marquart-Pyatt, 2011). Several of the cognitive/interpersonal barriers we identified, such as status quo bias and aesthetics, are also consistent with findings by Carolan (2005) and Ulrich-Schad et al. (2016). Our finding that NOLs' financial motivations act as a conservation barrier is also supported by Carolan et al. (2004) and Petrzelka and Marquart-Pyatt (2011).

While we observed several barriers that are consistent with existing scholarship, we also documented some conservation barriers that are new to scholarship on this subject. For example, negotiating lease terms very early relative to the beginning of the lease year, i.e., March 1 , resulted in uncertainties about commodity prices and renewal of leases, subsequently impacting

\footnotetext{
${ }^{6}$ Whereas study participants included NOLs and operators who had crop-share leases, none of our respondents cited barriers directly associated with this lease type, per se.
} 
conservation decision-making. Conservation barriers pertaining to rental market dynamics were also identified. Specifically, these barriers pertain to competitiveness of the rental markets and an asynchronous declining trend in commodity prices and rental rates. Conservation barriers such as NOLs' lack of awareness of rights and obligations and rental market competitiveness were newly documented barriers pertaining to information deficits/asymmetries. Moreover, we paid close attention to both barrier identification and attribution, conceptualized as barrier expression in our study. By interviewing four different groups - NOLs, operators, farm managers and university extension personnel - we were able to capture different perspectives on NOL-operator relationship. This is critical to advancing the literature on understanding conservation barriers on rented farmland, especially because the decision-making to overcome conservation barriers is a joint endeavor between NOL and operator, often involving farm managers and/or university extension personnel.

We do not argue that our list of conservation barriers is exhaustive. There could be other barriers this study did not reveal. Although we conducted 40 interviews with a broad spectrum of NOLs, operators, farm managers, and university extension personnel, an intentional limitation of our study design is that we are unable to make any causal or statistically generalizable claims about the relative significance of any given barrier overall, or the degree to which various subpopulations of operators and NOLs view any given barrier with respect to conservation adoption. However, by following a semi-structured interview format and asking questions about the NOLoperator relationship, we were able to both confirm previously documented barriers and reveal new barriers. While we provide several recommendations to overcome both the previously documented and newly identified conservation barriers, scholars and practitioners should treat 
these recommendations as hypotheses that need to be tested with broad-scale, quantitative research approaches.

Critical gaps remain in our understanding of the NOL-operator relationship, including the extent to which power differentials inform communication and decision-making. Scholars should consider using experimental approaches designed to test the efficacy of increasing the balance of power between NOLs and operators and its effects on conservation behavior. Some approaches for improving the balance of power might include building flexibility into cash rent lease terms and fostering NOL-operator communication channels that persist beyond just negotiating the terms of the lease. Another fruitful enquiry in understanding the NOL-operator relationship might be to understand the role of facilitators of this relationship, such as farm mangers, university extension personnel, rural appraisers, and lawyers. Whether these facilitators play the role of 'influencers' in promoting conservation behavior on rented farmland is an outstanding question for future scholarship. For practitioners, including conservation planners and policy makers, we suggest paying close attention to barriers that are clearly visible to some parties in the conservation decision-making environment, but remain invisible to others; for example, barriers related to information deficits/asymmetries are clearly visible to farm managers and university extension personnel as barriers, but remain largely invisible to NOLs (see Table 6 for additional examples). Accounting for such differential visibility of barriers could help practitioners design more targeted and effective education and outreach interventions directed towards NOLs. For barriers that are visible to all parties, this presents an opportunity for practitioners to offer programs that are both welcomed by and is popular among different parties.

Most importantly, our findings suggest that new programs should consider channeling significantly more resources towards empowering NOLs overall - specifically those designed to 
help NOLs exert more influence in conversations and decisions related to the adoption of conservation practices. Doing this will likely require considerable coordination among farm managers, university extension personnel, and other facilitators of the NOL-operator relationship - a nontraditional collaboration that itself will have to overcome its own set of institutional/sectoral and operational differences. Overcoming these differences to more effectively target and support NOLs, we argue, will only become more critical as the share of prime agricultural land farmed by operators increases. Future conservation initiatives advanced by policymakers, researchers, and practitioners, therefore, must more purposefully consider the NOL-operator relationship as an increasingly influential leverage point - alongside traditional emphases on operators - in the broader effort to protect soil and water resources.

\section{References}

Arbuckle, J.G., Valdivia, C., Raedeke, A., Green, J., Rikoon, J.S., 2009. Non-operator landowner interest in agroforestry practices in two Missouri watersheds. Agrofor. Syst. 75, 73-82. https://doi.org/10.1007/s10457-008-9131-8

Bigelow, D., Borchers, A., Hubbs, T., 2016. US Farmland Ownership, Tenure, and Transfer.

Carolan, M.S., 2005. Barriers to the adoption of sustainable agriculture on rented land: An examination of contesting social fields. Rural Sociol. 70, 387-413. https://doi.org/10.1526/0036011054831233

Carolan, M.S., Mayerfeld, D., Bell, M.M., Exner, R., 2004. Rented land Barriers to sustainable agriculture. J. soil water Conserv. 59, 70A-75A.

Carter, A., 2016. Placeholders and Changemakers: Women Farmland Owners Navigating Gendered Expectations. Rural Sociol. 00. https://doi.org/10.1111/ruso.12131

Charmaz, K., 2006. Constructing grounded theory: A practical guide through qualitative analysis. Sage.

Constance, D.H., Rikoon, J.S., Ma, J.C., 1996. Landlord Involvement in Environmental Decision-Making on Rented Missouri Cropland: Pesticide Use and Water Quality Issues. Rural Sociol. 61, 577-605. https://doi.org/10.1111/j.1549-0831.1996.tb00635.x

Cox, E., 2011. A Lease-Based Approach to Sustainable Farming, Part II: Farm Tenancy Trends and the Outlook for Sustainability on Rented Land. Drake J. Agric. L. 16, 5.

Finley, A.O., Kittredge, D.B., 2006. Thoreau, Muir, and Jane Doe: different types of private forest owners need different kinds of forest management. North. J. Appl. For. 23, 27-34. 
Gilbert, J., Beckley, T.M., 1993. Ownership and Control of Farmland: Landlord-Tenant Relations in Wisconsin. Rural Sociol. 58, 569-579. https://doi.org/10.1111/j.15490831.1993.tb00513.x

Maye, D., Ilbery, B., Watts, D., 2009. Farm diversification, tenancy and CAP reform: Results from a survey of tenant farmers in England. J. Rural Stud. 25, 333-342. https://doi.org/10.1016/j.jrurstud.2009.03.003

Pampel, F., van Es, J.C., 1977. Environmental quality and issues of adoption research. Rural Sociol. 42, 57.

Patton, M.Q., 1990. Qualitative Evaluation and Research Methods, 2nd ed. Sage Publications, Newbury Park, CA.

Petrzelka, P., 2012. Absentee landowners in the Great Lakes Basin: Who they are and implications for conservation outreach. Soc. Nat. Resour. 25, 821-832.

Petrzelka, P., Buman, T., Ridgely, J., 2009. Engaging absentee landowners in conservation practice decisions: A descriptive study of an understudied group. J. Soil water Conserv. 64, 94A-99A.

Petrzelka, P., Ma, Z., Malin, S., 2013. The elephant in the room: Absentee landowner issues in conservation and land management. Land use policy 30, 157-166. https://doi.org/10.1016/j.landusepol.2012.03.015

Petrzelka, P., Malin, S., Gentry, B., 2012. Absentee landowners and conservation programs: Mind the gap. Land use policy 29, 220-223. https://doi.org/10.1016/j.landusepol.2011.06.009

Petrzelka, P., Marquart-Pyatt, S., 2011. Land tenure in the U.S.: Power, gender, and consequences for conservation decision making. Agric. Human Values 28, 549-560. https://doi.org/10.1007/s10460-011-9307-0

Petrzelka, P., Sorensen, A., Filipiak, J., 2018. Women Agricultural Landowners-Past Time to Put Them “On the Radar.” Soc. Nat. Resour. 31, 853-864. https://doi.org/10.1080/08941920.2017.1423435

Reddy, S.M.W., Montambault, J., Masuda, Y.J., Keenan, E., Butler, W., Fisher, J.R.B., Asah, S.T., Gneezy, A., 2017. Advancing Conservation by Understanding and Influencing Human Behavior. Conserv. Lett. 10, 248-256. https://doi.org/10.1111/conl.12252

Rickenbach, M., Kittredge, D.B., 2009. Time and distance: comparing motivations among forest landowners in New England, USA. Small-Scale For. 8, 95-108.

Roesch-McNally, G.E., Arbuckle, J.G., Tyndall, J.C., 2018. Barriers to implementing climate resilient agricultural strategies: The case of crop diversification in the U.S. Corn Belt. Glob. Environ. Chang. 48, 206-215. https://doi.org/10.1016/j.gloenvcha.2017.12.002

Soule, M.J., Tegene, A., Wiebe, K.D., 2000. Land Tenure and the Adoption of Conservation Practices. Am. J. Agric. Econ. 82, 993-1005.

Srivastava, P., Hopwood, N., 2009. A Practical Iterative Framework for Qualitative Data 
Analysis. Int. J. Qual. Methods 8, 76-84. https://doi.org/10.1177/160940690900800107

U.S. Department of Agriculture Economic Research Service and National Agricultural Statistics Service (USDA-NASS), 2015. 2014 Tenure, Ownership and Transition of Agricultural Land (TOTAL).

Ulrich-Schad, J.D., Babin, N., Ma, Z., Prokopy, L.S., 2016a. Out-of-state, out of mind? Nonoperating farmland owners and conservation decision making. Land use policy 54, 602613. https://doi.org/10.1016/j.landusepol.2016.02.031

USDA-NRCS, 2018. Cover Crops and Soil Health [WWW Document]. URL https://www.nrcs.usda.gov/wps/portal/nrcs/detail/national/climatechange/?cid=stelprdb1077 238 (accessed 2.1.18). 